\title{
Effects of Molecular Weight Distribution on the Thermal Properties of Side-Chain Liquid Crystalline Poly(vinyl ether)s
}

\author{
Toshihiro SAGANE* and Robert W. LENZ \\ Polymer Science and Engineering Department, University of Massachusetts, \\ Amherst, MA 01003, U.S.A.
}

(Received May 2, 1988)

\begin{abstract}
Three biphenyl-containing vinyl ether monomers: 2-(4-biphenyloxy)ethyl vinyl ether (I), 2-(4-biphenylcarboxyl)ethyl vinyl ether (II), and 2-(4'-methoxy-4-biphenyloxy)ethyl vinyl ether (III), were cationically polymerized with the hydrogen iodide/iodine $\left(\mathrm{HI} / \mathbf{I}_{2}\right)$ initiator system to form living polymers with narrow molecular weight distributions. The thermal properties of the polymers were determined by DSC and by visual observations of samples placed on a hot stage on a polarizing microscope. Polymer I and Polymer II formed only isotropic melts, but Polymer III showed enantiotropic, liquid-crystalline (LC) behavior, and formed both smectic and nematic phases after one heating and cooling cycle. For comparison, polymers were also prepared with boron trifluoride etherate $\left(\mathrm{BF}_{3} \mathrm{OEt}_{2}\right)$ as the initiator. Polymer III obtained with this initiator had a much broader molecular weight distribution and formed only a nematic phase. At approximately the same molecular weight, this sample also had a much higher isotropization temperature than the narrow distribution sample of Polymer III.
\end{abstract}

KEY WORDS Side-Chain Liquid Crystalline Polymer / Poly(vinyl ether) / Cationic Living Polymerization / Biphenyl Group / 2-(4'-Methoxy-4biphenyloxy)ethyl Vinyl Ether / Molecular Weight Distribution / Monodisperse Polymer / Hydrogen Iodide-Iodine Initiator /

Liquid-crystalline polymers (LCP) can contain mesogenic units either in the main chain or in the side chain, and both types are of theoretical and practical interest. ${ }^{1}$ In contrast to the main chain LCP, the liquid-crystalline order of side chain LCP is generally closely related to that of the monomer, ${ }^{2}$ so side chain LCP are of value for investigations on the relationship between mesogenic unit structure and mesophase type in polymers as compared to low molecular weight mesogens.

Side-chain LCP can be prepared by three different routes including addition polymerization, condensation polymerization and post-reactions of polymers. ${ }^{2}$ Among the three methods, the most convenient approach is to introduce the mesogenic unit beforehand into a reactive monomer capable of undergoing addition or chain-growth polymerization. ${ }^{2}$ However, for the most part, the side chain LCP prepared by chain-growth polymerization have been limited to polymethacrylates, ${ }^{3}$ polyacrylates, ${ }^{3}$ and polystyrene derivatives, ${ }^{4}$ and very few of these investigations were concerned with the control and effect of molecular weight distribution on the properties of the LCP. One example of such control is the preparation of polymethacrylates by group-transfer polymerization, ${ }^{5}$ but the molecular weight distributions of these polymers

* Permanent address: Iwakuni Polymer Research Laboratory, Mitsui Petrochemical Industries, Ltd., Waki-cho, Kuga-gun, Yamaguchi 740, Japan. 
were still quite broad $\left(\bar{M}_{w} / \bar{M}_{n}=1.2-1.8\right)$.

Recently, Higashimura and coworkers have developed a new living cationic polymerization procedure for vinyl ethers and propenyl ethers using an $\mathrm{HI} / \mathrm{I}_{2}$ initiator system. ${ }^{6-8}$ By this technique, in contrast to conventional cationic polymerization, even vinyl ethers containing polar groups can be polymerized in a polar solvent such as $\mathrm{CH}_{2} \mathrm{Cl}_{2}$ to form living polymers. Our goal, therefore, was to prepare side chain LC poly(vinyl ethers)s with con- trolled molecular weight distributions by using this type of living cationic technique. If polymers with narrow distributions could be made in this manner, the effect of molecular weight on thermal properties could be determined without the undue influence of the component low and high molecular weight fractions. For this purpose, poly(vinyl ethers) were prepared by the living cationic polymerization of monomers containing biphenyl groups, including (I), (II), and (III) below:

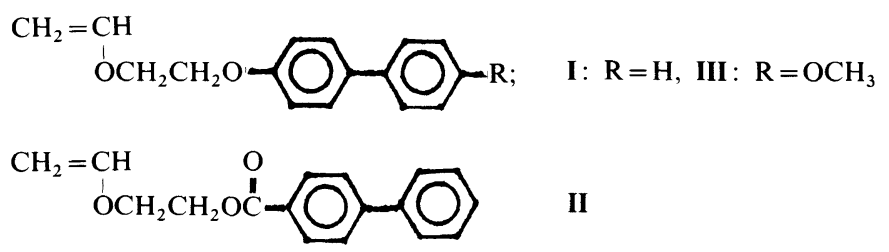

The cationic polymerization reactions of (I) and (III) ${ }^{9}$ initiated with conventional Lewisacids were previously reported, and as expected, these reactions yielded polymers with broad molecular weight distributions. Living cationic polymerization reactions of (I), (II), and (III), which were carried out in the present study, gave narrow molecular weight distributions, as described below.
Monomers (I), (II), and (III) were prepared by the phase transfer-catalyzed condensation of 2-chloroethyl vinyl ether with 4-phenylphenol, ${ }^{9}$ sodium-4-phenylbenzoate, ${ }^{10}$ and 4 (4'-methoxyphenyl)phenol, ${ }^{9}$ respectively, in the presence of a catalytic amount of tetrabutylammonium hydrogen sulfate or tetrabutylammonium iodide as shown below:

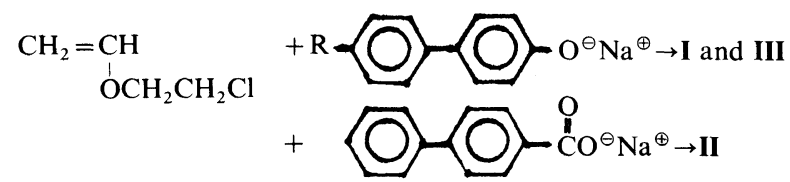

The three monomers were purified by recrystallization from methanol, and the melting points and the chemical shifts of the ${ }^{1} \mathrm{H}$ NMR spectra of the monomers are summarized in Table I.

\section{EXPERIMENTAL}

The hydrogen iodide $(\mathrm{HI})$, iodine $\left(\mathrm{I}_{2}\right)$, and boron trifluoride etherate $\left(\mathrm{BF}_{3} \mathrm{OEt}_{2}\right)$ initiators and the solvents (toluene, dichloromethane, and $n$-hexane) were purified and used as pre- viously reported. ${ }^{6}$

\section{Polymerization Procedures}

Cationic polymerization reactions were carried out in predried Schlenk tubes equipped with a three-way stopcock under a dry nitrogen atmosphere after the solid monomers were degassed. The reactions with $\mathrm{BF}_{3} \mathrm{OEt}_{2}$ were carried out by adding the initiator solution to the monomer solution, but for the $\mathrm{HI} / \mathrm{I}_{2}$ initiator, an $\mathrm{HI}$ solution in $n$-hexane was added to the monomer solution, and an iodine 
Side-Chain Liquid Crystalline Poly(vinyl ether)s

Table I. Characterization of the monomers

\begin{tabular}{|c|c|c|c|c|c|c|}
\hline \multirow{2}{*}{ Monomer } & \multirow{2}{*}{$T_{\mathrm{m}}^{\mathrm{a}} /{ }^{\circ} \mathrm{C}$} & \multirow{2}{*}{$T_{\mathrm{d}}^{\mathrm{b}} /{ }^{\circ} \mathrm{C}$} & \multirow{2}{*}{$T_{\mathrm{c}}^{\mathrm{b}} /{ }^{\circ} \mathrm{C}$} & \multicolumn{3}{|c|}{${ }^{1} \mathrm{H}$ NMR chemical shift } \\
\hline & & & & $\eta / \mathrm{ppm}$ & Proton $^{c}$ & Ratio \\
\hline \multirow{4}{*}{ (I) } & \multirow{4}{*}{79} & \multirow{4}{*}{ - } & \multirow{4}{*}{63} & $3.90-4.40(\mathrm{~m})$ & $\mathrm{a}, \mathrm{c}, \mathrm{d}$ & 6 \\
\hline & & & & $6.55(\mathrm{~d}$ of $\mathrm{d})$ & $\mathrm{b}$ & 1 \\
\hline & & & & $6.95-7.10(\mathrm{~m})$ & $\mathrm{e}$ & 2 \\
\hline & & & & $7.25-7.70(\mathrm{~m})$ & $\mathrm{f}, \mathrm{g}, \mathrm{h}, \mathrm{i}$ & 7 \\
\hline \multirow{7}{*}{ (II) } & --- & --- & --1 & ------- & ----1 & -- \\
\hline & \multirow{6}{*}{76} & \multirow{6}{*}{ - } & \multirow{6}{*}{37} & $4.05-4.25(\mathrm{~m})$ & $\mathrm{a}, \mathrm{c}$ & 4 \\
\hline & & & & $4.60(\mathrm{~m})$ & $\mathrm{d}$ & 2 \\
\hline & & & & $6.53(\mathrm{~d}$ of $\mathrm{d})$ & $\mathrm{b}$ & 1 \\
\hline & & & & $7.35-7.50(\mathrm{~m})$ & $\mathrm{h}, \mathrm{i}$ & 3 \\
\hline & & & & $7.60-7.70(\mathrm{~m})$ & $f, g$ & 4 \\
\hline & & & & $8.10-8.15(\mathrm{~m})$ & $\mathrm{e}$ & 2 \\
\hline \multirow{6}{*}{ (III) } & & & 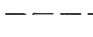 & ------- & ---- & - \\
\hline & & & & $3.82(\mathrm{~s})$ & $\mathrm{i}$ & 3 \\
\hline & & & & $3.90-4.35(\mathrm{~m})$ & $\mathrm{a}, \mathrm{c}, \mathrm{d}$ & 6 \\
\hline & 121 & $109^{d}$ & $105^{\mathrm{d}}$ & $6.55(\mathrm{~d}$ of $\mathrm{d})$ & $\mathrm{b}$ & 1 \\
\hline & & & & $6.85-7.05(\mathrm{~m})$ & $\mathrm{h}, \mathrm{e}$ & 4 \\
\hline & & & & $7.40-7.55(\mathrm{~m})$ & $f, g$ & 4 \\
\hline
\end{tabular}

a Determined by DSC (taken from the 2nd heating cycle thermogram).

b Determined by DSC (taken from the $1 \mathrm{st}$ cooling cycle thermogram). $T_{\mathrm{d}}$, deisotropization temp; $T_{\mathrm{c}}$, recrystallization temp.

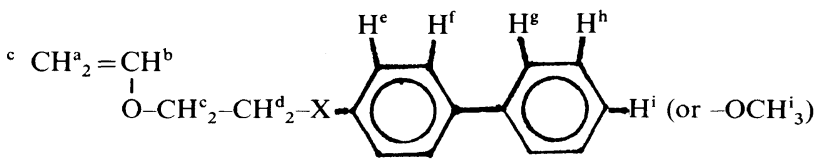

I, $\mathrm{X}=\mathrm{O}$; II, $\mathrm{X}=\mathrm{OC}(=\mathrm{O})$; III, $\mathrm{X}=\mathrm{O}$.

d Monotropic liquid crystalline phase was identified with the polarizing microscope (mosaic texture characteristic of smectic phase was observed).

solution was then added to this mixture to initiate polymerization. The reactions were terminated with cold ammoniacal methanol. The quenched polymerization solution was washed as previously reported, ${ }^{7}$ and the conversion of monomer was determined by gel permeation chromatography (GPC, see conditions shown below). All polymers were purified by precipitation from $\mathrm{CH}_{2} \mathrm{Cl}_{2}$ solutions into methanol and were dried in vacuum.

\section{Characterization of Monomers and Polymers}

The molecular weight distribution of the polymer was measured by GPC on samples in $\mathrm{CHCl}_{3}$ solutions on Waters Associates, Inc., liquid chromatograph equipped with five poly- styrene gel columns $(8 \mathrm{~mm} \times 23 \mathrm{~cm}$ each $)$ and a refractive index (RI) detector. The numberaverage molecular weight $\left(\bar{M}_{n}\right)$ was calculated with the use of a polystyrene calibration curve. ${ }^{1} \mathrm{H}$ and ${ }^{13} \mathrm{C}$ NMR spectra were obtained with Varian XL-200 and XL-300 spectrometers in $\mathrm{CDCl}_{3}$ at room temperature. In the ${ }^{13} \mathrm{C} \mathrm{NMR}$ spectra of the polymers, the absorptions of the methylene $\left(-\mathrm{CH}_{2}-\right)$ and the methine $(-\mathrm{CH}-)$ carbons in the main chain structure appear at $40.9,39.2\left(-\mathrm{CH}_{2}-\right)$ and $74.9 \mathrm{ppm}(-\mathrm{CH}-)$ for Polymer I; 40.6, $39.2\left(-\mathrm{CH}_{2}-\right)$ and $74.1 \mathrm{ppm}$ $(-\mathrm{CH}-)$ for Polymer II; 41.4, $40.8\left(-\mathrm{CH}_{2}-\right)$ and $74.1 \mathrm{ppm}(-\mathrm{CH}-)$ for Polymer III. The spectra also show that the signals of the pendant groups containing oxyethylene unit $\left(-\mathrm{CH}_{2}-\right.$ 
$\left.\mathrm{CH}_{2}-\mathrm{O}-\right)$, ethylene ester unit $\left(-\mathrm{CH}_{2}-\mathrm{CH}_{2}-\mathrm{O}-\right.$ $\mathrm{C}(=\mathrm{O})-$ ) and biphenyl group are exactly the same as those of corresponding monomers. All polymers also showed the expected ${ }^{1} \mathrm{H}$ NMR spectra.

Thermal analysis was carried out on a Perkin-Elmer DSC-2 instrument with polymer samples of about $10 \mathrm{mg}$ under a nitrogen flow at a scanning rate of $10^{\circ} \mathrm{C}$ per min. Indium and naphthalene were used for the calibration of the temperature scale. The melt behavior of the polymers was visually observed using a capillary melting point apparatus and a polarizing microscope equipped with crosspolarizers and a hot stage.

\section{RESULTS AND DISCUSSION}

The possibility of carrying out a living cationic polymerization of the biphenyl-containing vinyl ethers [monomers (I), (II), and (III)] was investigated using the $\mathrm{HI} / \mathrm{I}_{2}$ initiator system. A conventional cationic initiator, boron trifluoride etherate $\left(\mathrm{BF}_{3} \mathrm{OEt}_{2}\right)$, was also used as an initiator for comparison. The polymerization reactions of monomers (I), (II), and (III) by both initiators gave soluble polymers. Figure 1 shows the GPC plots of the molecular weight distributions of the polymers thus obtained. As reported by Higashimura and coworkers, for other vinyl ethers, ${ }^{11}$ the polymerization of monomers (I), (II), and (III) by $\mathrm{BF}_{3} \mathrm{OEt}_{2}$ gave broad distributions with $\bar{M}_{w} / \bar{M}_{n}$ values ranging from 2.5 to 3.0 , which are normal for cationic polymerization reactions. In contrast the $\mathrm{HI} / \mathrm{I}_{2}$ initiated polymers had very narrow distributions with $\bar{M}_{w} / \bar{M}_{n}$ ratios ranging from 1.2 to 1.4 .

Typical data for representative polymerization conditions and molecular weights of the polymers obtained are summarized in Table II. The living character of the polymerization reactions of (I), (II), and (III) initiated by the $\mathrm{HI} / \mathrm{I}_{2}$ system was indicated not only by the narrow distributions shown in Figure 1, but also by the relationship between polymerization reactants and number average molecular weight $\left(\bar{M}_{n}\right)$ in many cases and the observation that $\bar{M}_{n}$ of the polymers increased proportionally to the monomer-to-initiator feed molar ratio $\left([\mathrm{M}]_{0} /[\mathrm{HI}]_{0}\right)$ and to the molar ratio of monomer consumed-to-initiator, as shown by the data in Table II.

In spite of their bulky substituents, all three monomers could be readily polymerized by the $\mathrm{HI} / \mathrm{I}_{2}$ initiator system in the same manner as
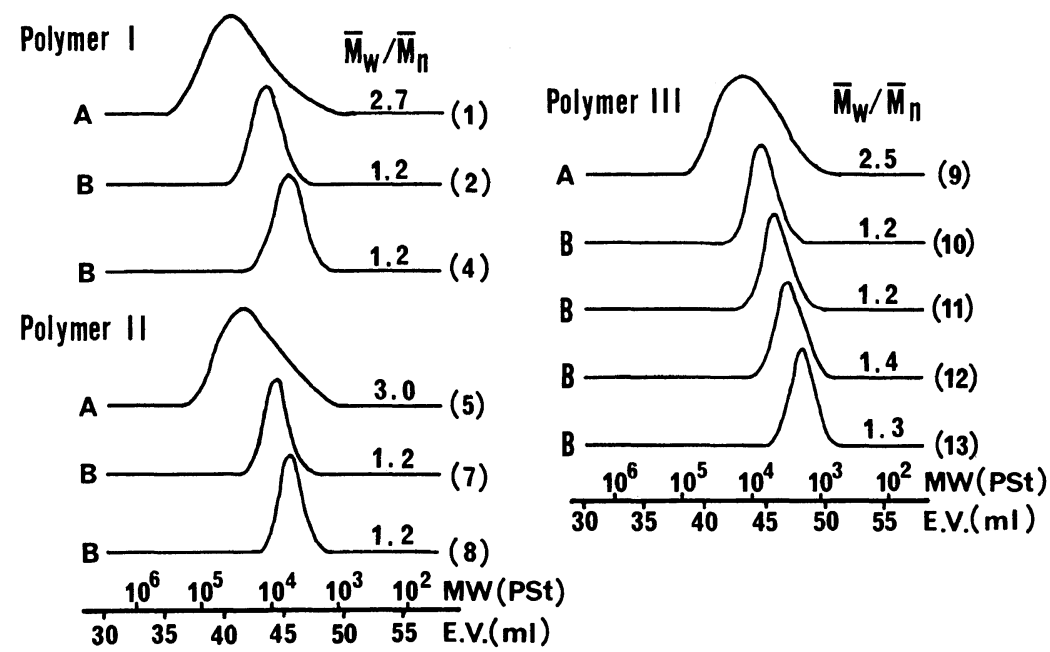

Figure 1. Molecular weight distributions of Polymers I, II, and III obtained by initiation with: (A) $\mathrm{BF}_{3} \mathrm{OEt}_{2}$ and $(\mathrm{B}) \mathrm{HI} / \mathrm{I}_{2}$; numbers in parentheses indicate the reaction number in Table II. 
Table II. Cationic polymerization of (I), (II), and (III) at $-15^{\circ} \mathrm{C}^{\mathrm{a}}$

\begin{tabular}{|c|c|c|c|c|c|c|c|}
\hline \multirow{2}{*}{$\begin{array}{l}\text { Reaction } \\
\text { No. }\end{array}$} & \multirow{2}{*}{ Monomer } & \multirow{2}{*}{$\begin{array}{c}\text { Initiator }(\mathrm{mM}) \text {, } \\
\text { solvent }^{\mathrm{b}}\end{array}$} & \multirow{2}{*}{$\frac{[\mathrm{M}]_{0}}{\mathbf{M}}$} & \multirow{2}{*}{$\begin{array}{c}\text { Reaction } \\
\text { time }^{\mathrm{c}} \\
\mathrm{h}\end{array}$} & \multicolumn{2}{|c|}{$\bar{M}_{n} \times 10^{-3}$} & \multirow{2}{*}{$\bar{M}_{w} / \bar{M}_{n}$} \\
\hline & & & & & Calcd $^{d}$ & Obsvd $^{e}$ & \\
\hline (1) & (I) & $\mathrm{BF}_{3} \mathrm{OEt}_{2}(10.0) T$ & 0.17 & 1.5 & - & 18 & 2.7 \\
\hline (2) & (I) & $\mathrm{HI} / \mathrm{I}_{2}(5.9 / 0.2) D$ & 0.25 & 48 & 10.2 & 12 & 1.2 \\
\hline (3) & (I) & $\mathrm{HI} / \mathrm{I}_{2}(8.4 / 10.0) T$ & 0.20 & 18 & 5.7 & 6.5 & 1.2 \\
\hline (4) & (I) & $\mathrm{HI} / \mathrm{I}_{2}(10.3 / 0.2) D$ & 0.21 & 2 & 4.9 & 5.4 & 1.2 \\
\hline (5) & (II) & $\mathrm{BF}_{3} \mathrm{OEt}_{2}(2.5) T$ & 0.15 & 3 & - & 11 & 3.0 \\
\hline (6) & (II) & $\mathrm{HI} / \mathrm{I}_{2}(8.9 / 0.2) D$ & 0.21 & 70 & 6.3 & 8.5 & 1.3 \\
\hline (7) & (II) & $\mathrm{HI} / \mathrm{I}_{2}(10.0 / 10.0) T$ & 0.21 & 48 & 5.6 & 7.6 & 1.2 \\
\hline (8) & (II) & $\mathrm{HI} / \mathrm{I}_{2}(20.0 / 20.0) T$ & 0.21 & 48 & 2.9 & 4.8 & 1.2 \\
\hline (9) & (III) & $\mathrm{BF}_{3} \mathrm{OEt}_{2}(2.5) T$ & 0.06 & 3 & - & 6.7 & 2.5 \\
\hline (10) & (III) & $\mathrm{HI} / \mathrm{I}_{2}(4.3 / 0.2) D$ & 0.11 & 162 & 6.9 & 6.0 & 1.2 \\
\hline (11) & (III) & $\mathrm{HI} / \mathrm{I}_{2}(2.9 / 3.0) T$ & 0.06 & 408 & 4.8 & 4.3 & 1.2 \\
\hline (12) & (III) & $\mathrm{HI} / \mathrm{I}_{2}(10.3 / 0.2) D$ & 0.11 & 3 & 2.9 & 2.4 & 1.4 \\
\hline$(13)^{f}$ & (III) & $\mathrm{HI} / \mathrm{I}_{2}(13.1 / 10.0) T$ & 0.11 & 24 & 2.3 & 1.8 & 1.3 \\
\hline
\end{tabular}

a All reaction conversions were close to $100 \%$ except for Reactions 11 , which was $85 \%$.

b Reaction solvents: $T$, toluene, $D$, dichloromethane.

c These values do not necessarily indicate the time when the monomer conversion reaches $100 \%$, but represent the time between the initiation and the termination.

d Calcd $\bar{M}_{n}=(\mathrm{MW}$ of monomer $) \times\left([\mathrm{M}]\right.$ consumed $\left./[\mathrm{HI}]_{0}\right)$.

e Determined by GPC calibrated with standard polystyrene samples.

${ }^{\mathrm{f}}$ Reaction run at $-5^{\circ} \mathrm{C}$.

other vinyl ethers ${ }^{11}$ to form polymers of the expected structure:

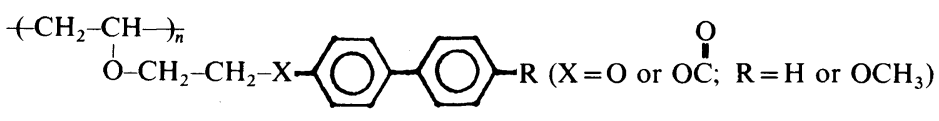

Thermal Properties of the Polymers

Typical DSC thermograms of Polymers I and II obtained by the $\mathrm{HI} / \mathrm{I}_{2}$ initiator are shown in Figure 2(A) and (B). Both polymers showed only $T_{\mathrm{g}}$ transitions; Polymer I at about $56^{\circ} \mathrm{C}$ and Polymer II at $32^{\circ} \mathrm{C}$. Neither polymer showed any indication of the presence of a crystalline or liquid crystalline endotherm in the thermograms. The $T_{\mathrm{g}}$ of Polymer I was the same as that previously reported. ${ }^{9}$

In contrast, the thermograms of all samples of Polymer III showed at least one endotherm and in some cases two, as seen in Figure 2(C) and (D) for the DSC thermograms of Polymer III obtained by initiation with $\mathrm{BF}_{3} \mathrm{OEt}_{2}$ and $\mathrm{HI} / \mathrm{I}_{2}$, respectively. The thermal transition data and calculated data for thermodynamic properties for all samples of Polymer III are collected together in Table III. The $\mathrm{BF}_{3} \mathrm{OEt}_{2}-$ initiated polymer showed a glass transition at $157^{\circ} \mathrm{C}$ and an endothermic transition peak, $T_{1}$, at $190^{\circ} \mathrm{C}$ in the first heating cycle and an exothermic transition peak, $T_{2}$, at $160^{\circ} \mathrm{C}$ in the first cooling cycle in Figure 2. An endothermic transition peak, designated $T_{5}$ in Figure 2, at $185^{\circ} \mathrm{C}$ was also observed in the second heating cycle.

The transition values of the $\mathrm{HI} / \mathrm{I}_{2}$-initiated polymers were different from those of the former. A glass transition at $134^{\circ} \mathrm{C}$ and an endothermic transition peak, $T_{1}$, at $174^{\circ} \mathrm{C}$ in the first heating cycle are seen in Figure 2, 
Table III. Thermal properties of broad and narrow (10-13) distribution samples of polymer III

\begin{tabular}{|c|c|c|c|c|c|c|c|c|c|c|c|}
\hline \multirow{3}{*}{$\begin{array}{c}\text { Reaction } \\
\text { No. }\end{array}$} & \multicolumn{5}{|c|}{ Thermal transitions $\left({ }^{\circ} \mathrm{C}\right)$ by DSC } & \multicolumn{6}{|c|}{ Thermodynamic parameters ${ }^{\mathrm{c}}$} \\
\hline & \multicolumn{3}{|c|}{ Heating cycle ${ }^{a}$} & \multicolumn{2}{|c|}{ Cooling cycle ${ }^{b}$} & \multicolumn{3}{|c|}{$\Delta H \times \mathrm{cal} \mathrm{g}^{-1}$} & \multicolumn{3}{|c|}{$\Delta S \times 10^{2}\left(\mathrm{calg}^{-1} \mathrm{~K}^{-1}\right)$} \\
\hline & $T_{\mathrm{g}}$ & $T_{\mathrm{s}-\mathrm{n}}$ & $T_{\mathrm{n}-\mathrm{i}}$ & $T_{\mathrm{i}-\mathrm{n}}$ & $T_{\mathrm{n}-\mathrm{s}}$ & $\Delta H_{\mathrm{s}-\mathrm{n}}$ & $\Delta H_{\mathrm{n}-\mathrm{i}}$ & $\Delta H_{\mathrm{s}-\mathbf{n}}+\Delta H_{\mathrm{n}-\mathrm{i}}$ & $\Delta S_{\mathrm{s}-\mathrm{n}}$ & $\Delta S_{\mathrm{n}-\mathrm{i}}$ & $\Delta S_{\mathrm{s}-\mathrm{n}}+\Delta S_{\mathrm{n}-\mathrm{i}}$ \\
\hline (9) & 157 & - & $\begin{array}{c}190 \\
(185)\end{array}$ & 160 & - & - & 11.9 & 11.9 & - & 2.6 & 2.6 \\
\hline$(10)$ & 138 & $\overline{(149)}$ & $\begin{array}{c}171 \\
(161)\end{array}$ & 130 & 123 & 5.3 & 6.9 & 12.2 & 1.3 & 1.6 & 2.8 \\
\hline (11) & 134 & - & $\begin{array}{c}174 \\
(160)\end{array}$ & 133 & 121 & 7.4 & 4.6 & 12.0 & 1.8 & 1.1 & 2.8 \\
\hline (12) & 130 & $(143)$ & $\begin{array}{c}169 \\
(159)\end{array}$ & 138 & 123 & 8.1 & 3.9 & 12.0 & 1.9 & 0.9 & 2.8 \\
\hline (13) & 128 & $\overline{(140)}$ & $\begin{array}{c}170 \\
(160)\end{array}$ & 140 & 122 & 8.3 & 4.1 & 12.4 & 2.0 & 0.9 & 3.0 \\
\hline
\end{tabular}

a Taken from the first heating cycle; numbers in parentheses indicate the transition temperatures taken from the second heating cycle.

b Taken from the first cooling cycle.

c Taken from the second heating cycle.

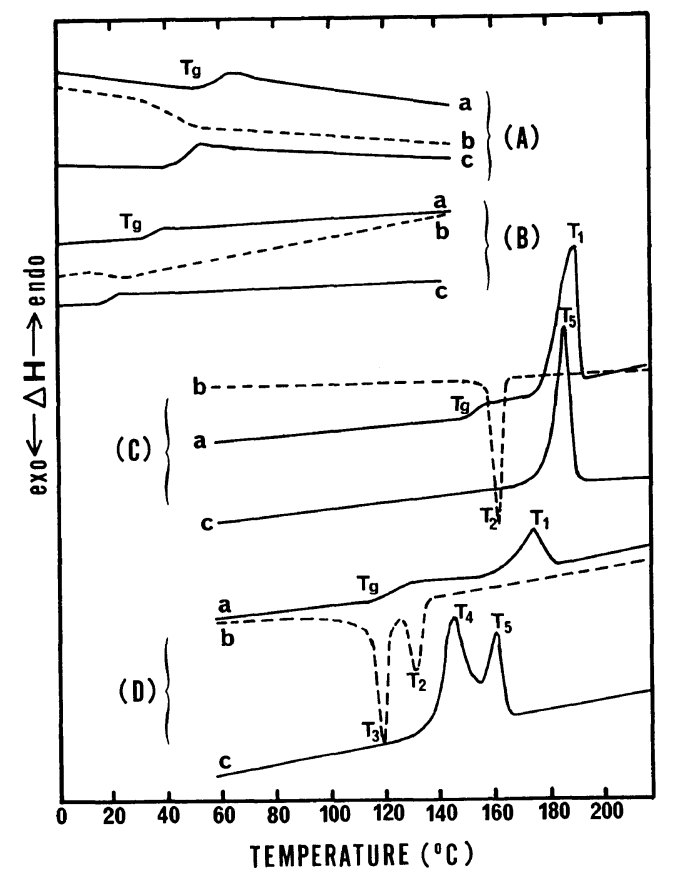

Figure 2. DSC thermograms of (A) Polymer I by $\mathrm{HI} / \mathrm{I}_{2}$, (B) Polymer II by $\mathrm{HI} / \mathrm{I}_{2}$, (C) Polymer III by $\mathrm{BF}_{3} \mathrm{OEt}_{2}$, and (D) Polymer III by $\mathrm{HI} / \mathrm{I}_{2}$. [(A) No. 4, (B) No. 6, (C) No. 9, (D) No. 11, in Table II; a) the first heating cycle, b) the first cooling cycle, c) the second heating cycle.] while two exothermic transition peaks, $T_{2}$ and $T_{3}$, at $133^{\circ} \mathrm{C}$ and $121^{\circ} \mathrm{C}$, respectively, are evident in the first cooling cycle. Two endothermic transition peaks, $T_{4}$ and $T_{5}$, are seen at $145^{\circ} \mathrm{C}$ and $160^{\circ} \mathrm{C}$ in the second heating cycle. After the first heating cycle, subsequent cycles on each polymer gave virtually identical DSC thermograms.

In order to identify the transition peaks $T_{1}$ to $T_{5}$ in the DSC thermograms of the polymer, texture observations were made of all samples of Polymer III with a polarizing microscope. The samples of the $\mathrm{BF}_{3} \mathrm{OEt}_{2}$-initiated polymer showed thread-like textures characteristics of the nematic phase ${ }^{12}$ at the temperature just below $T_{2}$ in the cooling cycle and just below $T_{5}$ (or $T_{1}$ ) in the heating cycle, as shown in the photomicrographs in Figure 3. On the other hand, Polymer III samples obtained with $\mathrm{HI} / \mathrm{I}_{2}$ showed both nematic, thread-like textures between $T_{2}$ and $T_{3}$ (also between $T_{4}$ and $T_{5}$ and just below $T_{1}$ ) and focal-conic textures characteristic of the smectic phase ${ }^{12}$ at temperatures just below $T_{3}$ (or $T_{4}$ ), as shown in the photomicrographs in Figure 4.

None of the samples of Polymer III ob- 


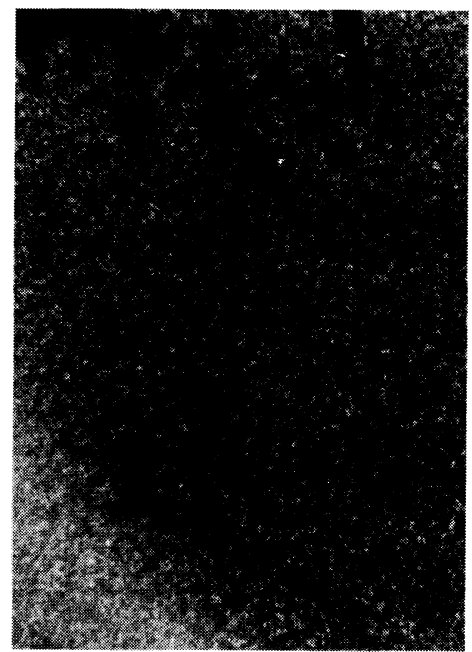

(A)

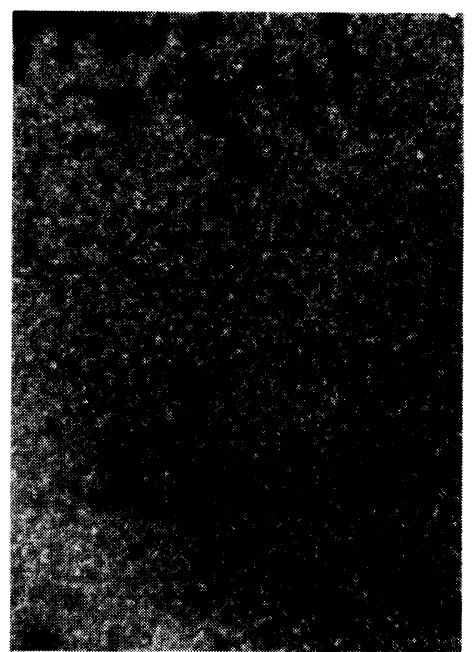

(B)

$100 \mu \mathrm{m}$

Figure 3. Micrographs of the nematic texture exhibited by Polymer III obtained by $\mathrm{BF}_{3} \mathrm{OEt}_{2}$ (No. 9 in Table II) in the first cooling cycle, (A) at $155^{\circ} \mathrm{C}$ (just below $T_{\mathrm{i}-\mathrm{n}}$ ), (B) after $30 \mathrm{~min}$ at the same temperature (original magnification: $320 \times$ ).

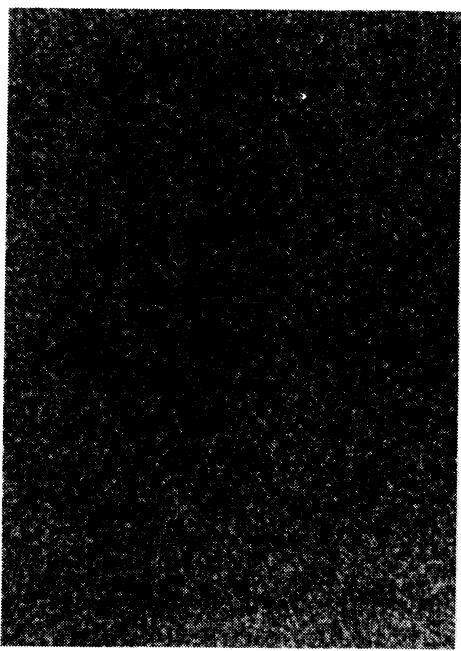

(A)

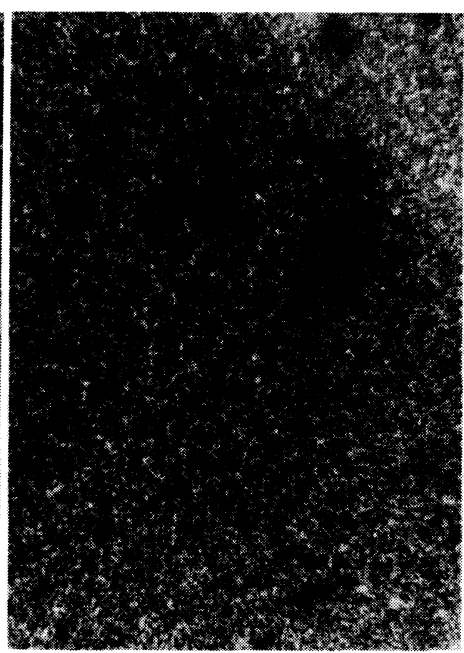

(B)

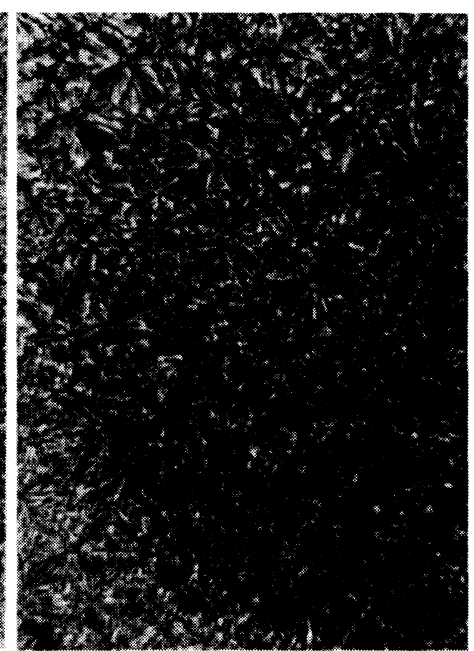

(c)

$100 \mu \mathrm{m}$

Figure 4. Micrographs of the nematic texture $[(\mathrm{A}),(\mathrm{B})]$ and the smectic texture $[(\mathrm{C})]$ of Polymer III obtained with the $\mathrm{HI} / \mathrm{I}_{2}$ initiator (No. 11 in Table II) in the first cooling cycle, (A) at $130^{\circ} \mathrm{C}$ (between $T_{\mathrm{i}-\mathrm{n}}$ and $T_{\mathrm{n}-\mathrm{s}}$ ), (B) after $30 \mathrm{~min}$ at the same temperature, (C) at $118^{\circ} \mathrm{C}$ (just below $T_{\mathrm{n}-\mathrm{s}}$ ); magnification is $320 \times$.

tained with either $\mathrm{BF}_{3} \mathrm{OEt}_{2}$ or $\mathrm{HI} / \mathrm{I}_{2}$ showed glass transitions in the DSC thermograms after the first heating cycle. The virgin polymers, which were obtained by precipitation from solution, were the only samples which showed a $T_{\mathrm{g}}$. The $T_{\mathrm{g}}$ transition may overlap with the 


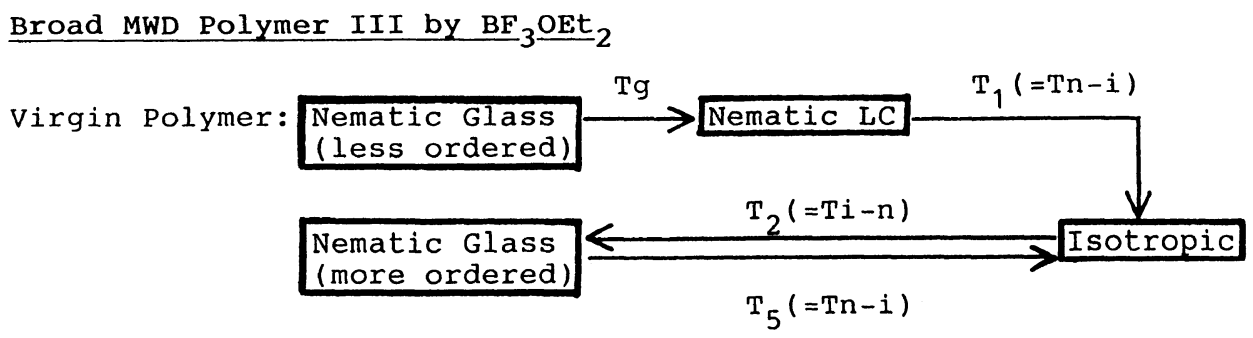

Narrow MWD Polymer III by $\mathrm{HI} / \mathrm{I}_{2}$

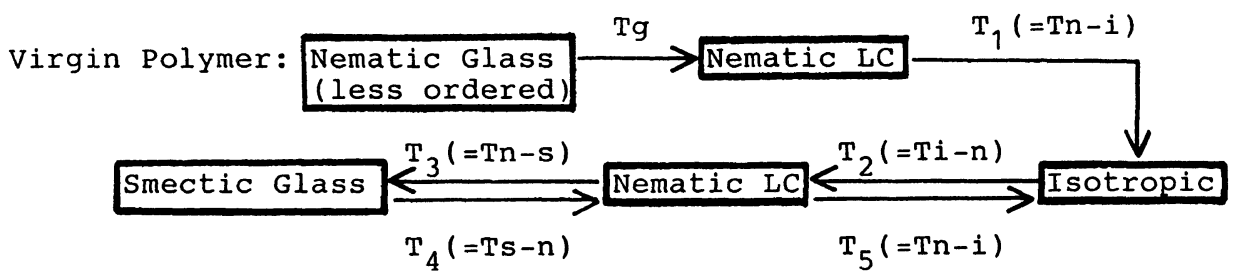

Figure 5. Schematic representations of the comparative thermal transitions of the broad and narrow distribution polymers.

$T_{2}$ (or $T_{5}$ ) transition in the $\mathrm{BF}_{3} \mathrm{OEt}_{2}$-initiated samples and with the $T_{3}$ (or $T_{4}$ ) in the $\mathrm{HI} / \mathrm{I}_{2}$ initiated samples after one heating cycle. That is, the $T_{\mathrm{g}}$ transition may have shifted to a higher temperature after the first heating and cooling cycle possible because the glassy state so formed differed from that of the virgin polymer. The virgin polymer as precipitated may have had either a poorly ordered nematic structure, or may have even been isotropic, while the glass formed after the first heating and cooling cycle may have been in an ordered nematic state (the $\mathrm{BF}_{3} \mathrm{OEt}_{2}$-initiated samples) or in a smectic state (the $\mathrm{HI} / \mathrm{I}_{2}$-initiated samples).

Each transition peak, and each phase before and after the peak, could be identified, and the transitions are represented in Figure 5, in which $T_{x-y}$ indicates the transition temperature from the $x$-phase to the $y$-phase. The assigned transitions are also indicated in Table III. Observations on a capillary melting point aparatus gave the same results.

\section{Molecular Weight Dependency}

The molecular weight $\left(\bar{M}_{n}\right)$ dependencies of the thermal transitions of Polymer III are shown by the data in Table III. The narrow MWD samples of Polymer III in the molecular weight range of 1,800 to 6,000 showed only a slight effect of $\bar{M}_{n}$ on $T_{\mathrm{g}}, T_{\mathrm{s}-\mathrm{n}}$, and $T_{\mathrm{i}-\mathrm{n}}$. Thus, $T_{\mathrm{g}}$ and $T_{\mathrm{s}-\mathrm{n}}$ increased and, surprisingly, $T_{\mathrm{i}-\mathrm{n}}$ decreased with increasing $\bar{M}_{n}$, but $T_{\mathrm{n}-\mathrm{i}}$ and $T_{n-s}$ were not affected by this molecular weight variation.

The data in Table III also indicates that there is some molecular weight dependency on the thermodynamic parameters, $\Delta H$ and $\Delta S$. That is, $\Delta H_{\mathrm{s}-\mathrm{n}}$ and $\Delta S_{\mathrm{s}-\mathrm{n}}$ decreased and $\Delta H_{\mathrm{n}-\mathrm{i}}$ and $\Delta S_{\mathrm{n}-\mathrm{i}}$ increased with increasing the $\bar{M}_{n}$, but the summations of $\Delta H_{\mathrm{s}-\mathrm{n}}+\Delta H_{\mathrm{n}-\mathrm{i}}$ and $\Delta S_{\mathrm{s}-\mathrm{n}}+\Delta S_{\mathrm{n}-\mathrm{i}}$ were not affected by changes in $\bar{M}_{n}$.

For the broad distribution sample of III, Polymer 9, obtained with the $\mathrm{BF}_{3} \mathrm{OEt}_{2}$ initiator, all of the observed transition temperatures were higher than those for the narrow distribution sample, but the $\Delta H$ and $\Delta S$ values for the transitions for the nematic glass phase to isotropic phase were almost the same level as the values of $\Delta H_{\mathrm{s}-\mathrm{n}}+\Delta H_{\mathrm{n}-\mathrm{i}}$ and $\Delta S_{\mathrm{s}-\mathrm{n}}+$ $\Delta S_{\mathrm{n}-\mathrm{i}}$, respectively, of the latter. Possibly the $T_{\mathrm{g}}$ and $T_{\mathrm{n}-\mathrm{i}}$ values are more strongly affected by the higher molecular weight frac- 
tion of the broad distribution samples, and considering the inverse relationship for the narrow fraction polymers, perhaps $T_{\mathrm{i}-\mathrm{n}}$ is affected more by the lower molecular weight fraction of the broad distribution. In contrast, the sum of the $\Delta H$ and $\Delta S$ value from the smectic to nematic to isotropic phases was not affected by the molecular weight of the polymer, as seen in the results for the narrow distribution polymer samples in Table III.

The possible sensitivity of the $T_{\mathrm{g}}$ transition of the broad distribution sample of Polymer 9 to the high molecular weight fraction may be responsible for the observation that it did not show a smectic phase. That is, the glass temperature of the nematic mesophase may be above the $T_{\mathrm{s}-\mathrm{n}}$ temperature for this polymer so that on cooling the polymer becomes immobile before it can rearrange to form the smectic phase. Hence, the presence of a higher molecular weight fraction may cause the resulting increase of the $T_{\mathrm{g}}$ of the nematic phase preventing the formation of the smectic mesophase. If so, this polymer would have a monotropic smectic phase relative to $T_{\mathrm{g}}$. Percec and coworkers reported ${ }^{9}$ that their sample of Polymer III, which was obtained with the $\mathrm{BF}_{3} \mathrm{OEt}_{2}$ initiator, showed a smectic texture below its isotropization temperature of $173^{\circ} \mathrm{C}$, but they did not observe a $T_{\mathrm{g}}$ for their polymer, and they did not report a molecular weight for their sample.

Acknowledgement. The authors are grateful to the National Science Foundation for the partial support of this work under NSF Grant DMR-8317949 and to Mitsui Petrochemical Industries, Ltd. (Japan) for the support of $\mathrm{T}$. Sagane. Valuable recommendations for carrying out living cationic polymerization reactions were received from Professor $T$. Higashimura, Dr. M. Sawamoto and Dr. S. Aoshima of the Department of Polymer
Chemistry, Kyoto University, Japan, and their help is gratefully acknowledged. Helpful discussions with Professor Jung-Il Jin of the Department of Chemistry, Korea University and technical support for the preparation of monomers from Mr. D. Hammel are especially appreciated.

\section{REFERENCES}

1. (a) A. C. Griffin and J. F. Johnson, Ed., "Liquid Crystals and Ordered Fluids," Vol. 4, Plenum, New York, N. Y., 1984.

(b) L. L. Chapoy, Ed., "Recent Advances in Liquid Crystalline Polymers," Elsevier, New York, N. Y., 1985.

2. H. Finkelmann, "Polymer Liquid Crystals," A Ciferri, W. R. Krinbaum, and R. B. Meyer, Ed., Academic Press, New York, N. Y., 1982, Chapter 2.

3. (a) H. Finkelmann and G. Rehage, Adv. Polym. Sci. 60/61, 99 (1984).

(b) V. P. Shibaev and N. A. Plate, Adv. Polym. Sci., 60/61, 173 (1984).

4. V. Percec, J. M. Rodriguez-Parada, and C. Ericsson, Polym. Bull., 17, 347 (1984).

5. W. Kreuder and O. W. Webster, Makromol. Chem., Rapid Commun., 7, 5 (1986).

6. M. Miyamoto, M. Sawamoto, and T. Higashimura, Macromolecules, 17, 265 (1984).

7. T. Enoki, M. Sawamoto, and T. Higashimura, $J$. Polym. Sci., Polym. Chem. Ed., 24, 2261 (1986).

8. (a) T. Higashimura, A. Tanizaki, and M. Sawamoto, J. Polym. Sci., Polym. Chem. Ed., 22, 3173 (1984).

(b) T. Higashimura, M. Miyamoto, and $\mathbf{M}$. Sawamoto, Macromolecules, 18, 611 (1985).

(c) T. Higashimura and M. Sawamoto, Makromol. Chem. Suppl., 12, 153 (1985).

9. J. M. Rodriguez-Parada and V. Percec, J. Polym. Sci., Polym. Chem. Ed., 24, 1363 (1986)

10. (a) K. Kato, T. Ichijo, and M. Hasegawa, J. Polym. Sci., $A-1,9,2109$ (1971).

(b) S. Watanabe and M. Kato, J. Polym. Sci., Polym. Chem. Ed., 22, 2801 (1984).

11. (a) S. Aoshima, O. Hasegawa, and T. Higashimura, Polym. Bull., 13, 229 (1985).

(b) S. Aoshima, O. Hasegawa, and T. Higashimura, Polym. Bull., 14, 417 (1985).

(c) T. Nakamura, S. Aoshima, and T. Higashimura, Polym. Bull., 14, 515 (1985).

12. D. Demus and L. Richter, "Textures of Liquid Crystals," Verlag Chemie, New York, 1978. 